\title{
Investigation of failure modes of explanted porcine valves in the mitral position
}

\author{
Kun Liu ${ }^{1,2 \#}$, Wentao Feng ${ }^{3 \#}$, Xianda Yang ${ }^{3}$, Jinglun Shen ${ }^{1,2}$, Haibo Zhang ${ }^{1,2}$, Yubo Fan ${ }^{3}$ \\ ${ }^{1}$ Department of Cardiac Surgery, Beijing Anzhen Hospital, Capital Medical University, Beijing, China; ${ }^{2}$ Capital Medical University, Beijing, China; \\ ${ }^{3}$ Key Laboratory for Biomechanics and Mechanobiology of Ministry of Education, Beijing Advanced Innovation Centre for Biomedical Engineering, \\ School of Biological Science and Medical Engineering, Beihang University, Beijing, China \\ Contributions: (I) Conception and design: H Zhang, Y Fan; (II) Administrative support: None; (III) Provision of study materials or patients: K Liu, H \\ Zhang, J Shen; (IV) Collection and assembly of data: W Feng, K Liu; (V) Data analysis and interpretation: W Feng, X Yang; (VI) Manuscript writing: \\ All authors; (VII) Final approval of manuscript: All authors. \\ "These authors contributed equally to this work. \\ Correspondence to: Haibo Zhang. Beijing Anzhen Hospital, Capital Medical University. No.2 Anzhen Road, Chaoyang District, Beijing 100029, \\ China. Email: zhanghb2318@163.com; Yubo Fan. School of Biological Science and Medical Engineering, Beihang University, No. 37 Xueyuan Road, \\ Haidian District, Beijing 100191, China. Email: yubofan@buaa.edu.cn.
}

Background: Porcine valves are used for mitral valve replacement, but the limited long-term durability has restricted the application in younger patients. Degenerated porcine mitral valves were explanted to analyze the failure modes and damage characteristics.

Methods: Twelve porcine valves were explanted via secondary mitral valve replacement surgery. Microcomputed tomography scanning, morphological and pathological examinations were performed to classify the cusp tears, calcification, and pannus formation. The causes of valve deterioration were subsequently analyzed.

Results: The mean age at first implantation was $45.42 \pm 19.58$ years (range, $11-64$ years). The mean duration of implantation was $9.39 \pm 4.14$ years (range, $4.25-18.75$ years). The indications for first surgery were rheumatic heart disease in 8 patients $(66.67 \%)$, infective endocarditis in 2 patients $(16.67 \%)$, degenerative valvular disease in one patient (8.33\%), and congenital heart disease in one patient $(8.33 \%)$. Type I cusp tears and commissural dehiscence that occurred near the stent post position were found in $6(50 \%)$ and $5(41.67 \%)$ valves, respectively. Calcification was detected in $6(50 \%)$ cases, and pannus was found in most valves (91.67\%).

Conclusions: Leaflet damage occurred near the stent posts area was the main failure mode of porcine mitral valves in this study. Patients who undergo the first surgery at younger age, the higher prevalence rate of rheumatic heart disease, the structure of bioprosthetic porcine valve, and left ventricular stresses could be considered as the main factors causing valve deterioration.

Keywords: Porcine mitral valve; structural valve deterioration; cusp tears; commissural dehiscence; explant analysis

Submitted Dec 25, 2020. Accepted for publication Mar 25, 2021.

doi: $10.21037 /$ jtd-20-3578

View this article at: http://dx.doi.org/10.21037/jtd-20-3578

\section{Introduction}

Porcine bioprosthetic valves have been widely used for mitral valve replacement since the 1960 s (1). Several manufacturers have adopted unique strategies and technologies for the design and manufacture of valves to improve hemodynamic performance and durability $(2,3)$. However, porcine valve deterioration depends on the implanted position. The mitral porcine valve is 
located between the left atrium and the left ventricle and is therefore exposed to left ventricular blood flow and pressure. Clinical follow-up studies of patients with bioprosthetic valves have shown that porcine mitral valves still have several problems in terms of freedom from reoperation, survival outcomes, and valve-related morbidity and mortality (4-6). To determine the underlying causes of porcine mitral valve deterioration, the present retrospective study reviewed the morphological and pathological features of porcine mitral valves after second valve replacements at one center.

We present the following article in accordance with the STROBE reporting checklist (available at http://dx.doi. org/10.21037/jtd-20-3578).

\section{Methods}

From September 2018 to December 2019, a total of 12 porcine mitral valves were explanted for analysis at our center (Beijing Anzhen Hospital, Capital Medical University, Beijing, China). All patients in this study were provided informed consent for undergoing the procedures. The study was conducted in accordance with the Declaration of Helsinki (as revised in 2013). The study design was approved by the Ethics Review Committee of Beijing Anzhen Hospital (No. 2020069x). The baseline characteristics of the patients (gender, age, age at first implantation, implant duration, age at revision surgery, and echocardiography results) and valve explants (valve brand, implantation site, and valve type) were obtained from the medical records. Echocardiography was performed to determine the porcine valve function preoperatively. The causes of valve dysfunction include structural valve deterioration (cusp tears, commissural dehiscence, and calcification), nonstructural valve deterioration (valvular endocarditis and pannus formation), thrombosis, and infection $(7,8)$.

\section{Morphological examination}

The explanted deteriorated valves were cleaned with $0.9 \%$ stroke-physiological saline solution and preserved with $4 \%$ paraformaldehyde. Cusp tears, commissural dehiscence and pannus were identified and classified by morphological examination. Based on the location and manner of leaflet tears, cusp tears were categorized into four types: type I (longitudinal tears involving free edges of the cusp), type II (parallel to the sewing ring), type III (large, round, or oval perforations at the center of the cusp), and type IV (several pinholes in the center of the cusp) (Figure 1) (9). Commissural dehiscence was regarded as separated leaflets from prosthetic stents without cusp tears (10). Pannus was divided into the following types: type I (located on the surface of the cusp), type II (covering $<2 \mathrm{~mm}$ of the surface of the cusp), type III (covering $>2 \mathrm{~mm}$ of the surface of the cusp), and type IV (very severe, surrounding the entire surface of the cusp and causing cusp contracture) (9).

\section{Microcomputed tomography scanning}

Microcomputed tomography (micro-CT) imaging has been used to identify small calcified tissues of porcine valves with high accuracy (11). All metals, plastics, and fabrics were removed from the explanted valves and only leaflet tissues were examined with micro-CT (Skyscan 1076, Bruker Corporation, MA, USA) to obtain two-dimensional layerby-layer images. Finally, three-dimensional reconstruction software (MIMICS 14.0, Materialise, Leuven, Belgium) was used to reconstruct the three-dimensional structure of the valve leaflets (12). The calcified parts were marked in red to distinguish between calcified and noncalcified leaflets. It is worth mentioning that all micro-CT scans were performed by experienced personnel blinded to the clinical outcomes. Calcifications were classified as type 0 (no calcification), type I (mild lesions and macrocalcification), type II (moderate nodules $<1 \mathrm{~mm}$ in diameter), type III (large solitary nodules $1-2 \mathrm{~mm}$ in size), and type IV (confluent nodules $>2 \mathrm{~mm}$ in diameter and capable of puncturing the cusp surface) $(9,13)$.

\section{Pathological examination}

Pathological examination was performed using specimen prepared from representative samples of leaflet tissue. Decalcification was necessary prior to pathological examination. All sections were embedded in paraffin, sectioned at $4 \mu \mathrm{m}$, and stained with hematoxylin and eosin (H\&E) (7), and the Von Kossa's method.

\section{Statistical analysis}

Comparisons of continuous variables are expressed as mean \pm standard deviation. The implant duration and patient age at first implantation were analyzed using $t$-tests. All statistical analyses were performed using SPSS version 26 (IBM Corporation, Armonk, NY, USA). Statistical 

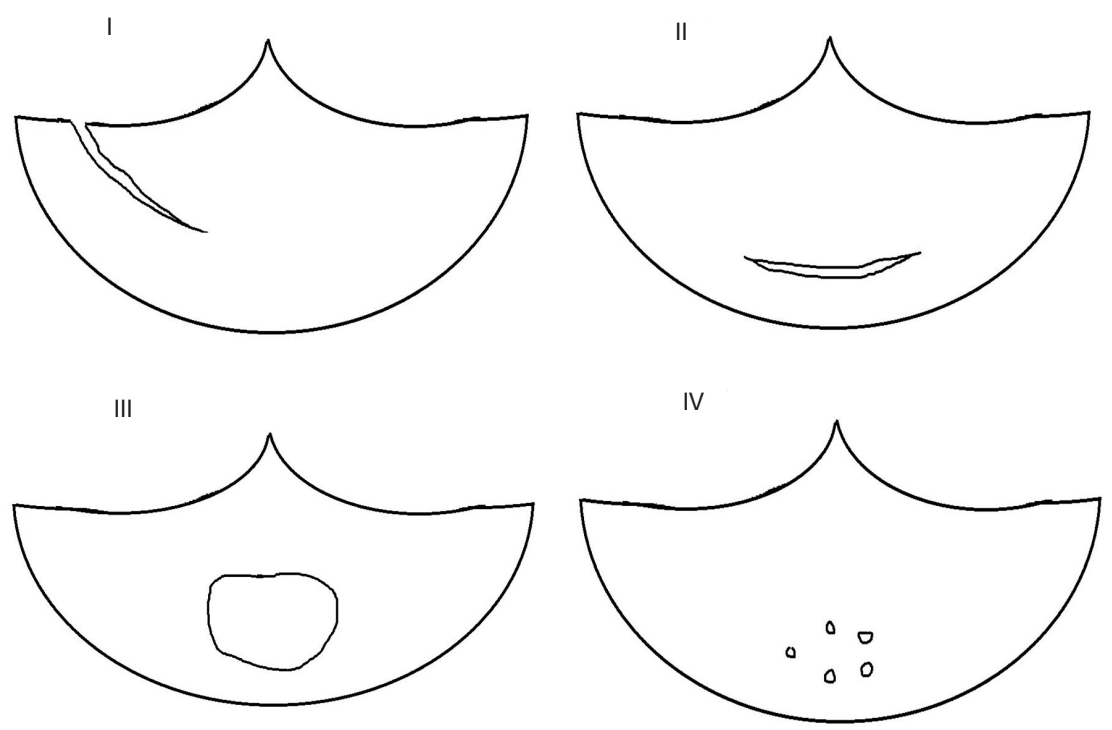

Figure 1 The different types of cusp tears. type I (longitudinal tear involving the free edges of the cusps), type II (along and parallel to the sewing ring), type III (large, round, or oval perforations at the center of the leaflets), type IV (several pinholes at the center of the leaflets).

Table 1 Patient basic characteristics

\begin{tabular}{|c|c|}
\hline Demographics and Characteristics & Porcine valves \\
\hline $\mathrm{N}$ & 12 \\
\hline Female, n (\%) & $9(75.00)$ \\
\hline Age (year) & $55 \pm 19.64$ \\
\hline Height (cm) & $165.58 \pm 5.4$ \\
\hline Weight (kg) & $62.42 \pm 9.3$ \\
\hline First surgery age (year) & $45.58 \pm 20.59$ \\
\hline Implant duration (year) & $9.39 \pm 4.14$ \\
\hline \multicolumn{2}{|l|}{ First surgery reason, $\mathrm{n}(\%)$} \\
\hline Rheumatic heart disease & $8(66.67)$ \\
\hline Infective endocarditis & $2(16.67)$ \\
\hline Degenerative valvular disease & $1(8.33)$ \\
\hline Congenital heart disease & $1(8.33)$ \\
\hline Hypertension, n (\%) & $5(41.67)$ \\
\hline Atrial fibrillation, n (\%) & $4(33.33)$ \\
\hline Coronary Heart Disease, n (\%) & $2(16.67)$ \\
\hline \multicolumn{2}{|l|}{ Valve size, $\mathrm{n}(\%)$} \\
\hline $25 \mathrm{~mm}$ & $3(25.00)$ \\
\hline $27 \mathrm{~mm}$ & $6(50.00)$ \\
\hline $29 \mathrm{~mm}$ & $3(25.00)$ \\
\hline
\end{tabular}

Values are presented as $\mathrm{n}(\%)$ or mean \pm SD. significance was set at $\mathrm{P}<0.05$.

\section{Results}

A total of 5 Hancock II (Medtronic Heart Valve Division, USA) porcine valves and 7 Carpentier-Edwards Supraannular (CE-SAV; Edwards Lifesciences Corporation, Irvine, CA, USA) porcine valves were explanted from 3 males (25\%) and 9 females (75\%). The baseline characteristics of the patients are listed in Table 1. The mean age was $55 \pm 19.64$ years (range, $18-74$ years). The mean age at first implantation was $45.42 \pm 19.58$ years, (range, 11-64 years). The indications for first surgery were rheumatic heart disease in 8 patients $(66.67 \%)$, infective endocarditis in 2 patients (16.67\%), degenerative valvular disease in one patient $(8.33 \%)$, and congenital heart disease in one patient $(8.33 \%)$. Four $(33.33 \%)$ patients took warfarin before the explantation due to atrial fibrillation. The mean implant duration was $9.39 \pm 4.14$ years (range, 4.25-18.75 years). Structural valve deterioration was found in $11(91.67 \%)$ valves, and nonstructural valve deterioration was found in one patient (8.33\%) (Table 2). There were no cases of valve deterioration due to thrombosis or infection.

Overall, 6 patients (50\%) showed one or more cusp tears (Figure 2). Only type I tears were found in the valve with cusp tears (Table 2). Commissural dehiscence accounted for valve dysfunction in 5 patients (41.67\%) (Figure 2, Table 2). 
Table 2 Pathologic findings of 12 porcine mitral valves

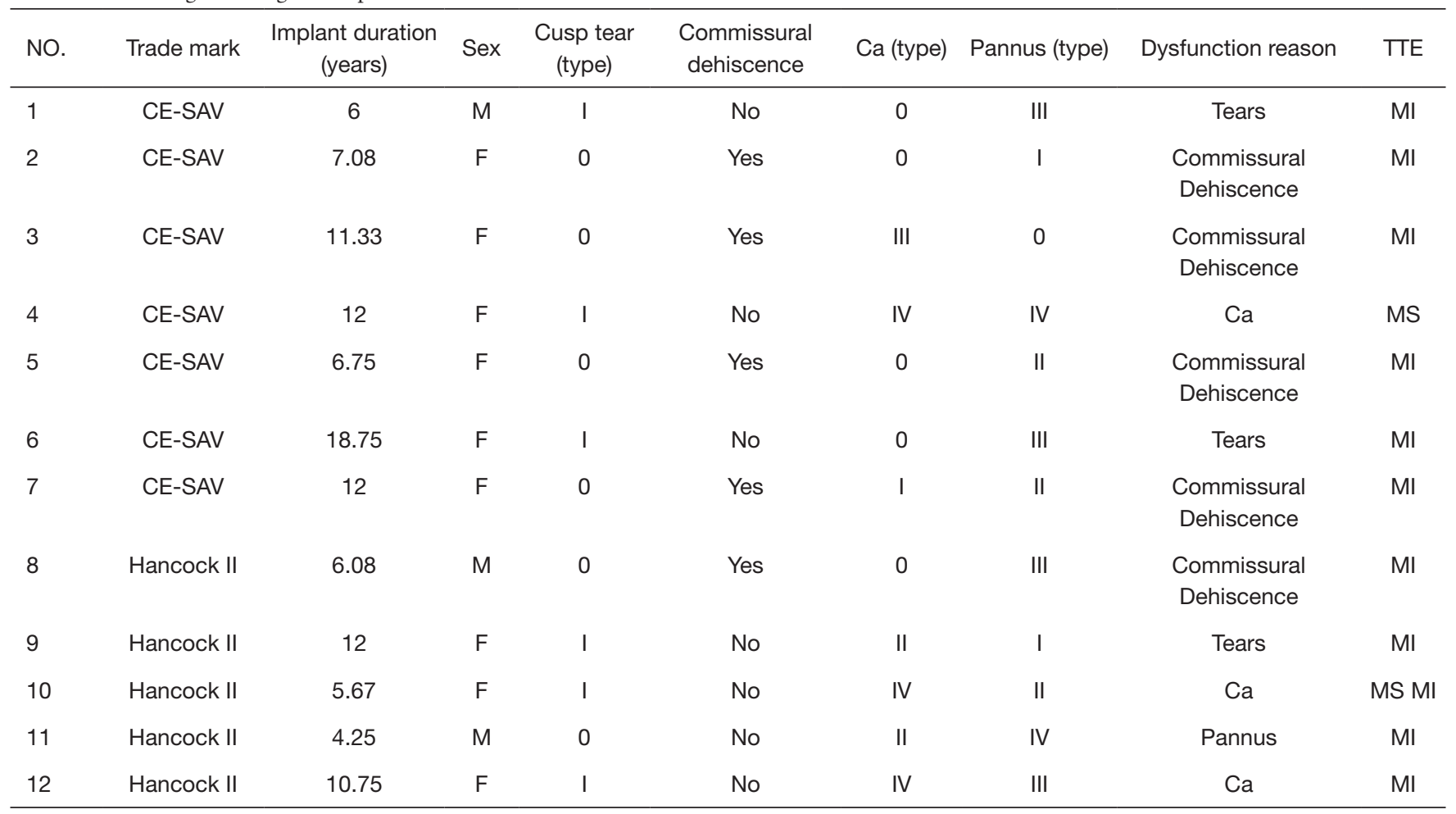

Ca, calcification; M, male; F, female; MI, mitral regurgitation; MS, mitral stenosis; TTE, transthoracic echocardiogram.
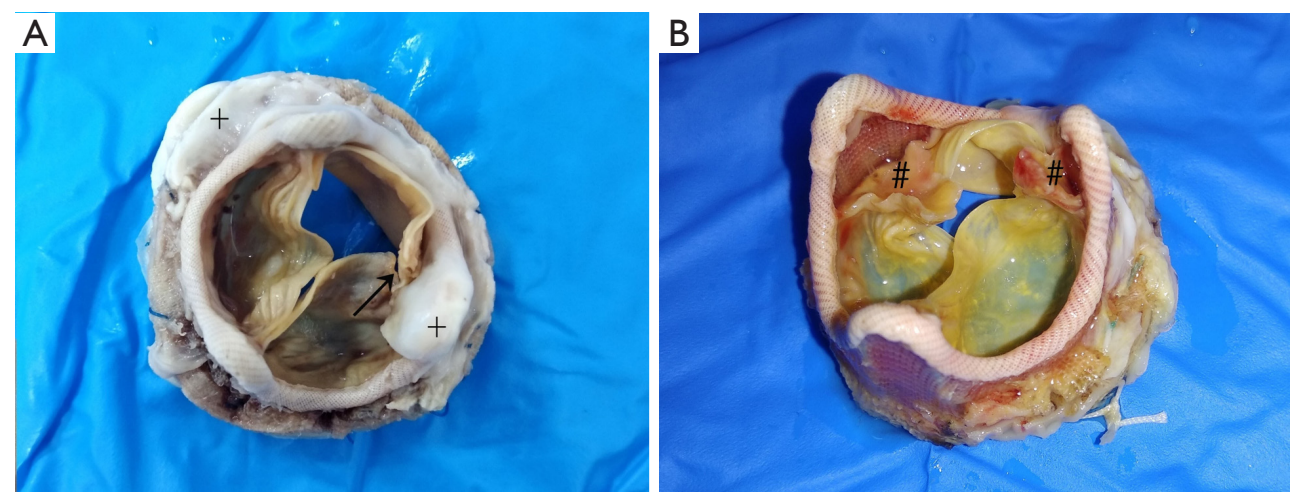

Figure 2 Leaflet deterioration near the stent posts (Type I tears and Commissural dehiscence). (A) Type I tear at the edge of valve leaflet (arrow); Pannus around the valve ring and stent (+); (B) Commissural dehiscence at the apex of the valve stent (\#).

Echocardiography demonstrated mitral regurgitation in the porcine mitral valves with cusp tears and commissural dehiscence.

Among the 12 porcine mitral valves, 7 (58.33\%) valves showed some degree of calcification. Of these 7 valves, $14.29 \%(n=1)$ showed type I calcification, $28.57 \%(n=2)$ showed type II calcification, $14.29 \%(\mathrm{n}=1)$ showed type III calcification and $42.85 \%(n=3)$ showed type IV calcification
(Figure 3, Table 2). The mean implant duration was $9.94 \pm 2.89$ years for moderate and severe calcified valves and $9.11 \pm 4.8$ years for other valves (no significant difference, $\mathrm{P}=0.763$ ). There was a significant difference in the mean patient age at first implantation between moderate and severe calcified valves and other valves $(23.25 \pm 18.84 \mathrm{vs}$. $56.5 \pm 9.15$ years; $\mathrm{P}=0.032$ ).

Pannus was found on the leaflet surface in 11 (91.67\%) 


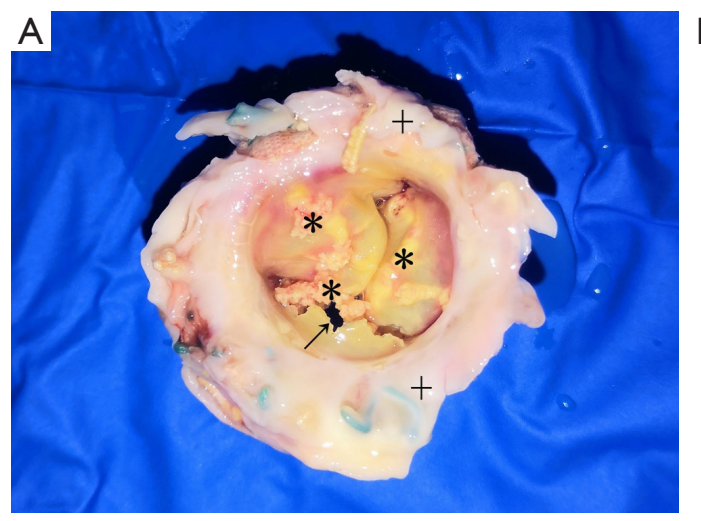

B

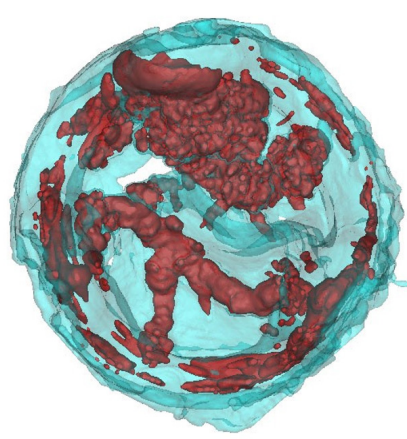

Figure 3 Calcification in the Hancock II porcine valve. (A) Calcification in valve leaflets with valve tears (*), indicating cusp tears (arrow); Pannus around the valve ring (+); (B) Microcomputed tomography scanning, three-dimensional reconstruction; red part indicates calcification in valve leaflets.

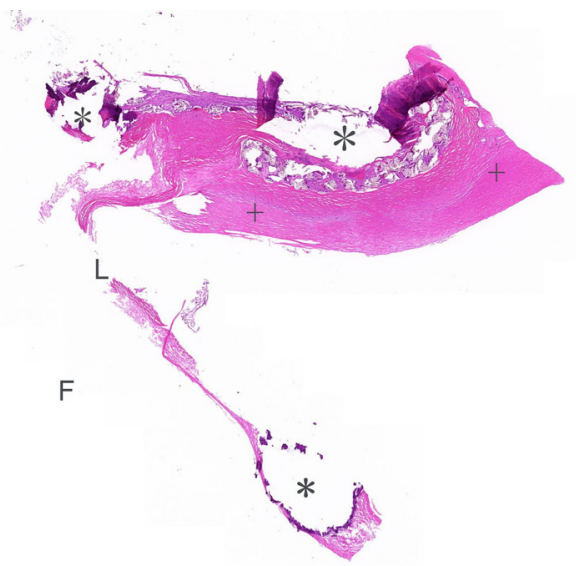

Figure 4 Pathological staining of the valve leaflet. The black parts represent calcified tissue, type IV $\left(^{*}\right)$, pannus covering the surface of the leaflet (+). F, Inflow; L, valve leaflet (original magnification, $\times 1.5$; hematoxylin and eosin).

porcine mitral valves (Figure 4), including 2 valves with type I ,3 with type II, 4 with type III and 2 with type IV (Table 2). In other words, pannus formation on the surfaces of mitral valves appeared to be a universal phenomenon in the explanted porcine mitral valves. However, only one porcine valve was damaged by pannus formation.

\section{Discussion}

Compared with mechanical valves, the lower risks of thromboembolic and hemorrhagic complications are the major advantage for bioprosthetic valves (14). However, the durability of bioprosthetic valve remains a major factor restricting the wide application in young patients $(15,16)$. Due to the anatomical structure of the mitral valve, the modes of porcine valve deterioration may be affected by left ventricular blood flow and pressure (17-19). Furthermore, due to the asymmetry of porcine native aortic valve leaflets, the structure of porcine valves would affect the stress distribution and blood flow pattern, and consequently affect the long-term durability of porcine valves (20).

Type I cusp tears and commissural dehiscence occurred near the stent post position in $91.67 \%$ of explanted valves which was the main mode of failure in the porcine mitral valves in the present study. The damage rate near the stent posts was higher than that reported by Naqvi et al. (21) (91.67\% vs. 42\%). This may be due to patients who undergo the first surgery at younger age, high prevalence rate of rheumatic heart disease, the structure of bioprosthetic porcine valve, and left ventricular stresses. The patient's average age at first surgery was lower than that reported by Naqvi et al. (21) $(45.42 \pm 19.58$ vs. $58.53 \pm 12.4$ years). In young patients, energetic physical activity may be an important reason of valve tear. In our study, $66.67 \%$ $(\mathrm{n}=8)$ patients underwent mitral valve replacement due to rheumatic heart disease which accounts for a major portion of valvular disease in China $(22,23)$. We found that the cusp tear was the only failure reason of explants from rheumatic heart disease patients, while the failure modes of explants from other patients who without rheumatic heart disease were usually tears caused by calcification. The rheumatic disease may affect the strength of collagenous fibers of leaflets, result in cusp tears. Chew et al. (24), who studied 
the mechanical features of porcine valve models, found that the porcine valve was subjected to the highest stress near the stent post area leading to leaflet tears, and that the stress at the tip of the tear increased with the length of the tear so that the degree of cusp tear would increase. Sun et al. (25) took advantage of the finite element method and experimental measurements to confirm that the maximum stress on the tri-leaflet valve was located near the stent posts in the closed state. The localized stress concentration at the stent position occurred in both porcine and bovine pericardial valves. However, the rate of cusp tears was lower among bovine pericardial valves. In a study of bovine pericardial valves, leaflet tears near the stent post area constituted a low proportion of the explanted valves $(17.36 \%)$ (9). It has been indicated that porcine valves have thinner leaflets and lower mechanical properties than bovine pericardial valves (26). Bovine pericardial valves can bear higher levels of stress due to the material properties near the stent posts; however, porcine valves are more susceptible to leaflet tears. The method of suturing porcine valve has also been proposed as a factor that contributes to commercial dehiscence. Bottio et al. (10) showed that the mode of stitching the leaflets onto the stent may affect commissural dehiscence in different types of porcine valves. The stress concentration at the sutures also undermines the stability of valve leaflets near the stent posts, leading to commercial dehiscence at the attachment site of the porcine valve to the stent (3). In a study of porcine aortic valves (aortic valves, 61.3\%; mitral valves, 35.6\%; and others, $3.1 \%$ ), Butany et al. (27) showed that $71.16 \%$ of porcine valves were damaged near the stent posts and the rate of mitral valve rupture was greater than that of aortic valve rupture. The left ventricle exerted greater pressure on the mitral valve than on the aortic valve. When the valve was closed, the orifice area of the mitral valve was larger than that of the aortic valve. Consequently, the total stress on the mitral valve was larger than that on the aortic valve during the entire cardiac cycle. In China, a large proportion of patients suffered from hypertension and the awareness and control rates of hypertension remained lower than in North American (28). In our study, $41.67 \%$ of the patients had hypertension. Hypertension increases the stretch ratio of the valve leaflets and causes the leaflets to tear easily.

Calcification was noted in $58.33 \%$ of the extracted porcine mitral valves and all patients with first surgery age less than 50 years have severe (type IV) leaflet calcification. Valve calcification was correlated with age at first implantation but not with implant duration in our study. These were also shown in Naqvi et al. study (21). Younger patients with bioprosthetic valves were more prone to valve deterioration induced by calcification. High rate of rheumatic heart disease as the reason of first mitral valve replacement was shown in our study. Rheumatic heart disease with young age accounts for a major portion of valvular disease in China $(22,23)$. With the lack of experience with mitral valve repair technology in the past decade, some young women underwent bioprosthetic valves implantations due to fertility requirements, which also contributed to the younger age of the patients. Although the specific mechanism responsible for this observation is unclear, it could be hypothesized that increased calcium metabolism and serum osteocalcin levels in young adults are responsible for the acceleration in valve calcification $(29,30)$. In a study of 45 porcine aortic valves, Butany et al. (31) noted that more severe and earlier calcification was observed in aortic valves than in mitral valves $(\mathrm{P}=0.03)$. It appears that the porcine mitral valve may be damaged by left ventricular pressure and blood flow in the early period of calcification formation. Hemodynamic disorders may not be observed even in moderate formations of calcification in porcine aortic valves. In severely calcified valves, calcified tissues may drop from the calcified leaflets, leading to embolization (32). In contrast to the $\mathrm{X}$-ray findings, some calcification spots were found in the valve leaflets on microCT scans (Figure 3). This may have led to the neglect of small calcified tissues and underestimation of the degree of calcification in previous studies. It is worth studying the classification and evaluation of calcified tissue further.

Pannus is mainly characterized by collagen and elastic fibrous tissue covering the valve surface, which thickens and fuses the valve leaflets, thereby limiting the movement of the valve leaflet and further leading to leaflets stiffness and valve stenosis (7). Pannus was presented in $91.67 \%$ of the valves, whereas valve deterioration was noted in only one valve (10\%). Butany et al. (27) reported that the probability of pannus formation was $95.7 \%$ among porcine valves. In addition, Kuniyoshi et al. indicated that $75.86 \%$ of mitral bioprosthetic valves had pannus. Pannus formations were prevalent in bioprosthetic valves which were attached to the fabric of the annulus and valve stent. Although the specific mechanism underlying the formation of pannus remains unclear, it may entail a non-immune inflammatory response to foreign bodies (33). Several studies have confirmed that the following factors contribute to pannus formation: the prosthetic valve design, surgical technique, small annulus, and flow turbulence (34-36). 


\section{Study limitations}

The present study investigated porcine mitral valves after explantation for valve deterioration. After valve deterioration, some people may decide not to undergo a second valve replacement operation or die due to other reasons. In addition, the progress of new interventional valve replacement technologies such as transcatheter valvein-valve implantation has eliminated the need for a second thoracotomy, preventing explantation of the damaged valve. Therefore, it was difficult to obtain enough valves. Furthermore, valve deterioration is a complex process associated with a vast variety of risk factors. These risk factors could not be considered in the present study due to patient-related characteristics.

\section{Conclusions}

The present study demonstrated that leaflet damage near the stent posts area was the main failure mode of porcine mitral valves in this study. Patients who undergo the first surgery at younger age, higher prevalence rate of rheumatic heart disease, the structure of bioprosthetic porcine valve, and left ventricular stresses could be considered as the main factors causing valve deterioration could be considered as the main factors causing valve damage near the stent post. Valve calcification was correlated with age at first implantation but not with implant duration in our study. Patients who undergo the first surgery at younger age was due to the high rate of rheumatic heart disease and younger women with fertility requirements. Therefore, we should fully consider the clinical factors and structure features of the mitral bioprosthetic valves in future studies.

\section{Acknowledgments}

Funding: This study was funded by Beijing Municipal Education Foundation (KZ201810025036); Beijing Natural Science Foundation (D171100002917003); National Key Research and Development Program of China (2017YFB0702500); Innovation Teams in Priority Areas Accredited by the Ministry of Science and Technology (11421201); SpecialFunded Program on National Key Scientific Instruments and Equipment Development (11827803).

\section{Footnote}

Reporting Checklist: The authors have completed the
STROBE reporting checklist. Available at http://dx.doi. org/10.21037/jtd-20-3578

Data Sharing Statement: Available at http://dx.doi. org/10.21037/jtd-20-3578

Peer Review File: Available at http://dx.doi.org/10.21037/jtd20-3578

Conflicts of Interest: All authors have completed the ICMJE uniform disclosure form (available at http://dx.doi. org/10.21037/jtd-20-3578). The authors have no conflicts of interest to declare.

Ethical Statement: The authors are accountable for all aspects of the work in ensuring that questions related to the accuracy or integrity of any part of the work are appropriately investigated and resolved. All patients in this study were provided informed consent for undergoing the procedures. The study was conducted in accordance with the Declaration of Helsinki (as revised in 2013). The study design was approved by the Ethics Review Committee of Beijing Anzhen Hospital (No. 2020069x).

Open Access Statement: This is an Open Access article distributed in accordance with the Creative Commons Attribution-NonCommercial-NoDerivs 4.0 International License (CC BY-NC-ND 4.0), which permits the noncommercial replication and distribution of the article with the strict proviso that no changes or edits are made and the original work is properly cited (including links to both the formal publication through the relevant DOI and the license). See: https://creativecommons.org/licenses/by-nc-nd/4.0/.

\section{References}

1. Binet JP, Carpentier A, Langlois J. Clinical use of heterografts for replacement of the aortic valve. J Thorac Cardiovasc Surg. 1968;55:238-42.

2. Bapat V, Mydin I, Chadalavada S, et al. A guide to fluoroscopic identification and design of bioprosthetic valves: A reference for valve-in-valve procedure. Catheterization and Cardiovascular Interventions 2013;81:853-61.

3. Vesely I. The influence of design on bioprosthetic valve durability. J Long Term Eff Med Implants 2001;11:137-49.

4. Rizzoli G, Mirone S, Ius P, et al. Fifteen-year results with the Hancock II valve: a multicenter experience. J Thorac 
Cardiovasc Surg 2006;132:602-9.e6094.

5. Jamieson WR, Burr LH, Munro AI, et al. CarpentierEdwards standard porcine bioprosthesis: a 21-year experience. Ann Thorac Surg 1998;66:S40-3.

6. Valfrè C, Ius P, Minniti G, et al. The fate of Hancock II porcine valve recipients 25 years after implant. Eur J Cardiothorac Surg 2010;38:141-6.

7. Akins CW, Miller DC, Turina MI, et al. Guidelines for reporting mortality and morbidity after cardiac valve interventions. Eur J Cardiothorac Surg 2008;33:523-8.

8. Capodanno D, Petronio AS, Prendergast B, et al. Standardized definitions of structural deterioration and valve failure in assessing long-term durability of transcatheter and surgical aortic bioprosthetic valves: a consensus statement from the European Association of Percutaneous Cardiovascular Interventions (EAPCI) endorsed by the European Society of Cardiology (ESC) and the European Association for Cardio-Thoracic Surgery (EACTS). Eur Heart J 2017;38:3382-90.

9. Butany J, Nair V, Leong SW, et al. Carpentier-Edwards Perimount valves-Morphological findings in surgical explants. J Card Surg 2007;22:7-12.

10. Bottio T, Valente M, Rizzoli G, et al. Commissural dehiscence: A rare and peculiar cause of porcine valve structural deterioration. J Thorac Cardiovasc Surg 2006;132:1017-22.

11. Chitsaz S, Gundiah N, Blackshear C, et al. Correlation of calcification on excised aortic valves by micro-computed tomography with severity of aortic stenosis. J Heart Valve Dis 2012;21:320.

12. Ho ST, Hutmacher DW. A comparison of micro CT with other techniques used in the characterization of scaffolds. Biomaterials 2006;27:1362-76.

13. Butany J, Zhou T, Leong SW, et al. Inflammation and infection in nine surgically explanted Medtronic Freestyle $\AA$ stentless aortic valves. Cardiovasc Pathol 2007;16:258-67. Erratum in: Cardiovasc Pathol. 2008;17:128.

14. Chikwe J, Chiang YP, Egorova NN, et al. Survival and outcomes following bioprosthetic vs mechanical mitral valve replacement in patients aged 50 to 69 years. JAMA 2015;313:1435-42.

15. Carrel TP, Englberger L. Mechanical versus bioprosthetic mitral valve replacement in patients younger than 65 years. J Thorac Cardiovasc Surg 2014;147:853-4.

16. Kaneko T, Cohn LH, Aranki SF. Tissue valve is the preferred option for patients aged 60 and older. Circulation 2013;128:1365-71.
17. Fukuta H, Little WC. The cardiac cycle and the physiologic basis of left ventricular contraction, ejection, relaxation, and filling. Heart Fail Clin 2008;4:1-11.

18. Faludi R, Szulik M, D'hooge J, et al. Left ventricular flow patterns in healthy subjects and patients with prosthetic mitral valves: an in vivo study using echocardiographic particle image velocimetry. J Thorac Cardiovasc Surg 2010;139:1501-10.

19. Akiyama K, Nakamura N, Itatani K, et al. Flow-dynamics assessment of mitral-valve surgery by intraoperative vector flow mapping. Interact Cardiovasc Thorac Surg 2017;24:869-75.

20. Grande KJ, Kunzelman KS, Cochran RP, et al. Porcine aortic leaflet arrangement may contribute to clinical xenograft failure. ASAIO J 1993;39:918-22.

21. Naqvi TZ, Siegel RJ, Buchbinder NA, et al. Echocardiographic and pathologic features of explanted Hancock and Carpentier-Edwards bioprosthetic valves in the mitral position. Am J Cardiol 1999;84:1422-7.

22. Zhimin W, Yubao Z, Lei S, et al. Prevalence of chronic rheumatic heart disease in Chinese adults. Int J Cardiol 2006;107:356-9.

23. Carapetis JR. Rheumatic heart disease in Asia. Circulation 2008;118:2748-53.

24. Chew GG, Howard IC, Patterson EA. Simulation of damage in a porcine prosthetic heart valve. J Med Eng Technol 1999;23:178-89.

25. Sun W, Abad A, Sacks MS. Simulated bioprosthetic heart valve deformation under quasi-static loading. J Biomech Eng 2005;127:905-14.

26. Soares JS, Feaver KR, Zhang W, et al. Biomechanical behavior of bioprosthetic heart valve heterograft tissues: Characterization, simulation, and performance. Cardiovasc Eng Technol 2016;7:309-51.

27. Butany J, Leong SW, Cunningham KS, et al. A 10-year comparison of explanted Hancock-II and CarpentierEdwards supraannular bioprostheses. Cardiovasc Pathol 2007;16:4-13.

28. Wang Z, Chen Z, Zhang L, et al. Status of hypertension in China: results from the China hypertension survey, 20122015. Circulation 2018;137:2344-56.

29. Schoen FJ, Levy RJ. Calcification of tissue heart valve substitutes: progress toward understanding and prevention. Ann Thorac Surg 2005;79:1072-80.

30. Shen M, Carpentier SM, Cambillau M, et al. Protein adsorption in glutaraldehyde-preserved bovine pericardium and porcine valve tissues. Ann Thorac Surg 2001;71:S408-9.

31. Butany J, Yu W, Silver M, et al. Morphologic findings in 
explanted Hancock II porcine bioprostheses. J Heart Valve Dis 1999;8:4.

32. Walley VM, Giannoccaro P, Beanlands DS, et al. Death at cardiac catheterization: Coronary artery embolization of calcium debris from lonescu-shiley bioprosthesis. Cathet Cardiovasc Diagn 1990;21:92-4.

33. Kuniyoshi Y, Koja K, Miyagi K, et al. Pannus formation in aortic valve prostheses in the late postoperative period. J Artif Organs 2003;6:179-82.

34. Hirota M, Isomura T, Yoshida M, et al. Subvalvular Pannus

Cite this article as: Liu K, Feng W, Yang X, Shen J, Zhang H, Fan Y. Investigation of failure modes of explanted porcine valves in the mitral position. J Thorac Dis 2021;13(5):2858-2866. doi: 10.21037/jtd-20-3578
Overgrowth after Mosaic bioprosthesis implantation in the aortic position. Ann Thorac Cardiovasc Surg 2016;22:108-11.

35. Vitale N, Renzulli A, Agozzino L, et al. Obstruction of mechanical mitral prostheses: analysis of pathologic findings. Ann Thorac Surg 1997;63:1101-6.

36. Renzulli A, De Luca L, Caruso A, et al. Acute thrombosis of prosthetic valves: a multivariate analysis of the risk factors for a life threatening. Eur J Cardiothorac Surg 1992;6:412-20. 